\title{
Gesundheitsbezogene Register - Wo steht die Schweiz?
}

\section{Esther Kraft}

Leiterin Abteilung DDQ

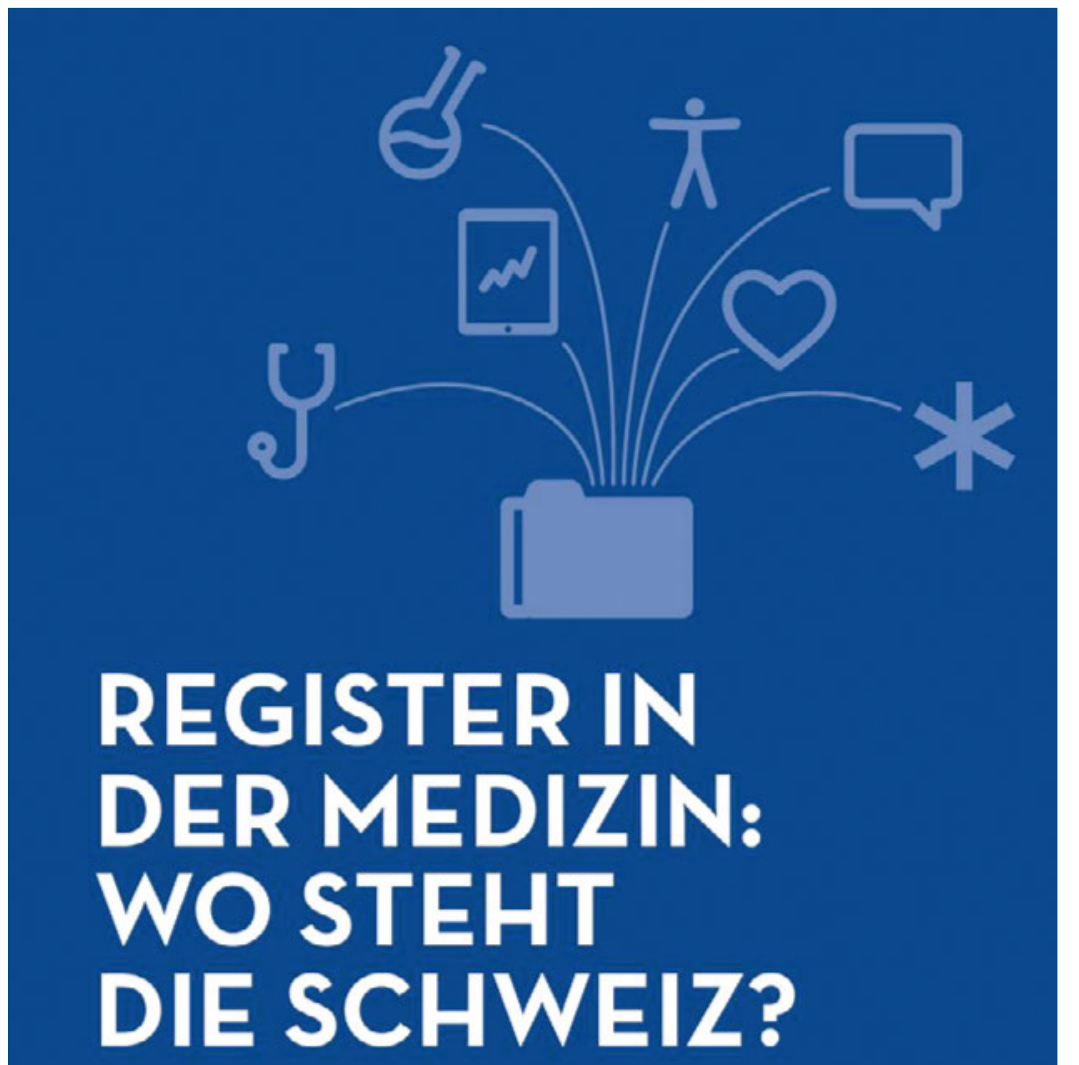

Donnerstag 1. Februar 2018, UniS Bern, Schanzeneckstrasse 1

Eine gemeinsame Veranstaltung der

Dialoggruppe Versorgungsforschung ISPM,

FMH, KKA und NewIndex

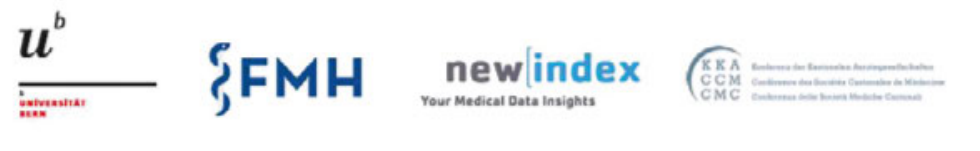

Um wissenschaftliche, von Partikulärinteressen unabhängige Grundlagen schaffen zu können, unterstützen die Verbindung der Schweizer Ärztinnen und Ärzte (FMH), die Konferenz der Kantonalen Ärztegesellschaften (KKA) sowie NewIndex gemeinsam den Forschungsschwerpunkt Versorgungsforschung am ISPM Bern. Eine Dialoggruppe dient als Informations- und Austauschplattform: Vertreter der Organisationen und der Forschungsgruppen diskutieren regelmässig die laufenden und geplanten Arbeiten im Bereich der Versorgungsforschung. Die gesundheitsbezogenen Register sind eines der aktuellen Themen der Dialoggruppe. Qualitativ hochstehende gesundheitsbezogene Register sind u.a. zentral für die Evaluation der Behandlungsqualität sowie zur Beurteilung von Versorgungsstrukturen. Zudem liefern sie wichtige Daten für die Gesundheitspolitik und -planung. Entsprechend gewinnen gesundheitsbezogene Register sowohl in der Schweiz als auch im Ausland immer mehr an Bedeutung.

Die Dialoggruppe (Institut für Sozial- und Präventivmedizin Bern, FMH, KKA, NewIndex) lädt Sie herzlich zur gemeinsamen Veranstaltung "Gesundheitsbezogene Register - Wo steht die Schweiz?» vom 1. Februar 2018 in Bern ein.

Es erwartet Sie ein abwechslungsreiches Programm mit nationalen und internationalen Experten aus der Wissenschaft, der Politik und der Leistungserbringung.

Sie finden das detaillierte Programm und die Anmeldung unter www.saqm.ch

Wir freuen uns, Sie am 1. Februar 2018 in Bern begrüssen zu dürfen.

Bildnachweis FMH 